\title{
Numerical investigation of manufacturing hollow preforms by combining the processes backward cup extrusion and piercing
}

\author{
Robinson Henry ${ }^{1, a}$ and Mathias Liewald ${ }^{1}$ \\ ${ }^{1}$ Institute for Metal Forming Technology, University Stuttgart, 70174 Stuttgart, Germany
}

\begin{abstract}
Hollow or tubular preforms are used to meet lightweight requirements and reduce production costs of cold formed components. In order to increase efficiency of manufacturing, a combined forming process was developed, which will be presented in this paper: manufacturing of hollow preforms by combining processes backward cup extrusion and piercing. With regard to combined forming processes in the field of cold forging, disclosed work consists of numerical identification of significant process input variables, process outcomes, and the process limits.
\end{abstract}

\section{Introduction}

In general, cold forged components can contribute essentially to diverse lightweight strategies when it comes to increasing the efficiency of manufacturing processes with regard to the use of material. Furthermore, the use of material can be reduced using the occurring cold work hardening and the process-specific possibility of creating a continuous grain structure, which is designed for specific loads. Generally, a reduction of material use of cold forged components while maintaining the functional demands is realized by using hollow designs.

Drive shaft and main shaft are typical components for cold forged parts, which are applied in the power train and chassis systems of modern vehicles. These cold forged parts must withstand high specific operating loads and have to fulfill high demands regarding tolerances in form, dimension, and position.

A resource-efficient production is necessary in order to fulfill the high demands for environmental-friendly production. These days, when producing hollow cold or hollow hot forged parts, a resource-efficient and costsaving process sequence inevitably starts using a hollow preforms or producing a hollow preforms in order to avoid subsequent machining operation after the process. Multi-stage forming processes are used frequently when producing preforms. For example, combining the processes upsetting, centering, backward cup extrusion, and piercing are used to produce a hollow preform [1].

Resulting from the functional separation of the inner and outer geometry of the relevant tool elements of sequential forming steps, the produced hollow preforms are not in the right position (e.g. figure 1a) This positional error (e.g. figure 1a) cannot be compensated for by further forming operations and therefore requires an additional machining process, which reduces the balance of the resource efficiency of the process and causes economical disadvantages. When producing hollow preforms the combination of two or more cold forming processes, regardless if they are the same processes or different ones (e.g. figure 1b), in one single tool has an advantage: during the same press stroke no functional separation of the inner and outer geometry of relevant tooling elements occurs resulting from multiple forming steps [2]. Additionally, the production costs can be decreased by reducing the number of forming steps and required forming tools in a physical meaning

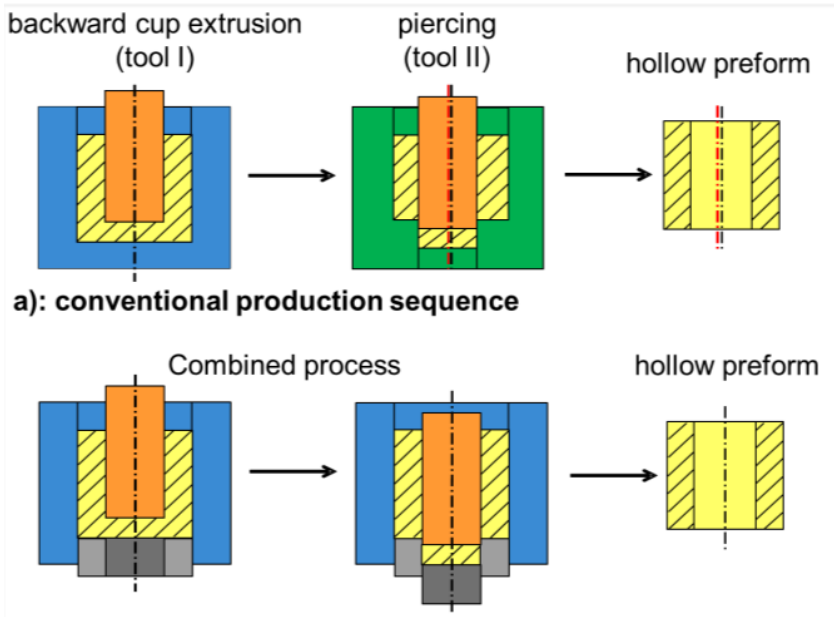

b): combined process of backward cup extrusion and piercing

Figure 1. Conventional (a) and combined process (b) routes .

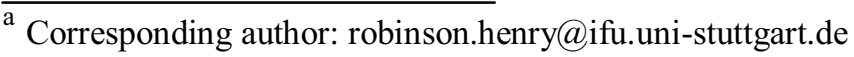



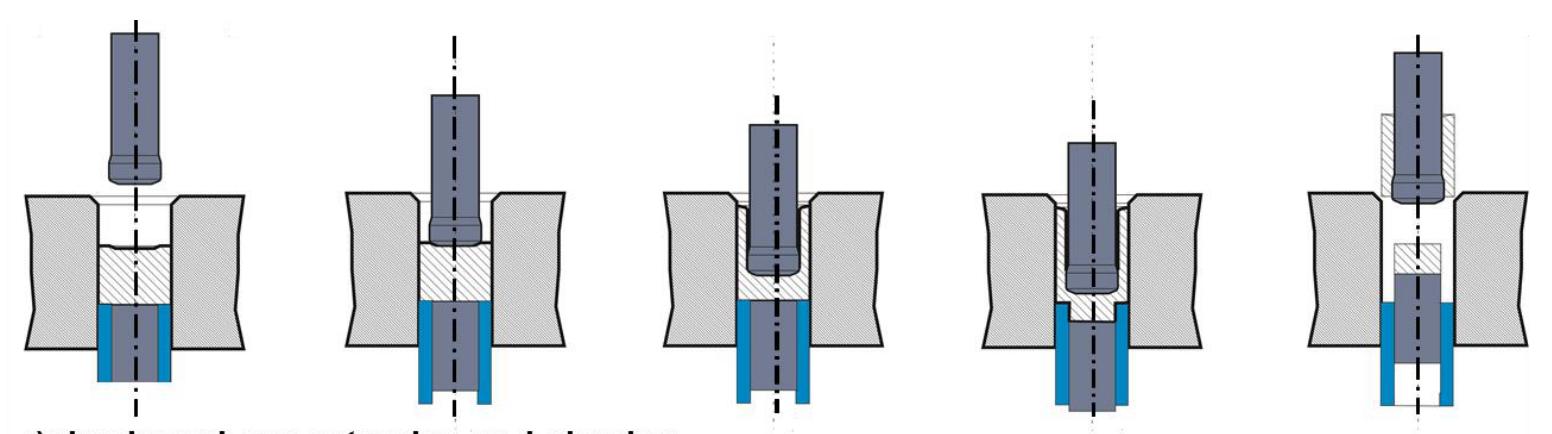

a): backward cup extrusion and piercing
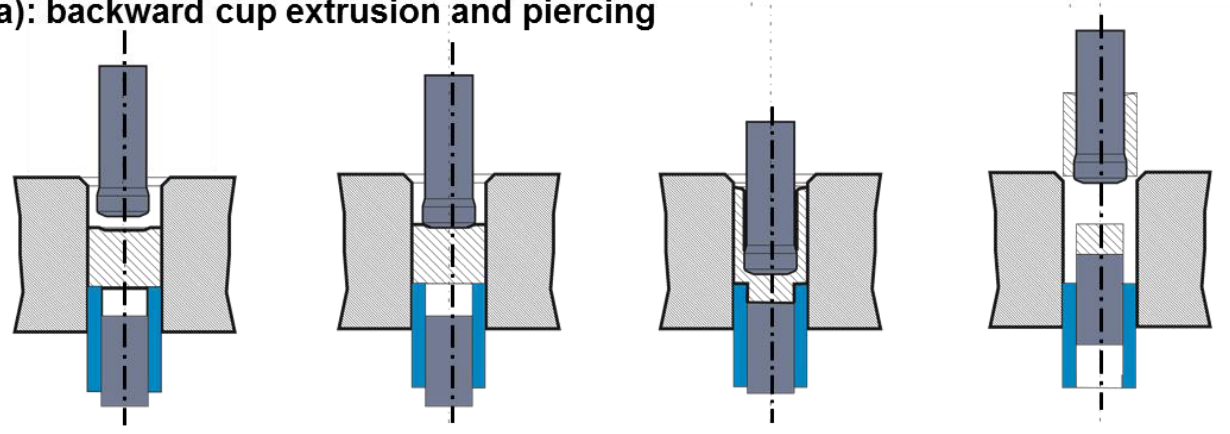

b): backward cup extrusion, penetrating and piercing

Figure 2. Combined process and tooling (punch)

In principle, two types of combined forming processes has been are investigated in this research project. The first variation of process is the combination of backward cup extrusion and piercing (e.g. figure 2a). A controlled movement of the counter punch can be performed to generate a hydrostatic stress state in the shearing zone during the piercing.

The second forming process is a combination of backward cup extrusion, penetrating, and piercing. A controlled movement of the counter punch is performed from the beginning of the backward cup extrusion process (e.g. figure $2 b$ ). The start of the piercing process is important with regard to the technical aspects. As part of the numerical investigation of the combination of backward cup extrusion and piercing, the influence of various parameters on the target variables (material flow, stroke force, process limits, temporal and local determination of crack initiation) during the piercing operation are investigated. The mechanical load of the experimental tooling is to be determined. Within this publication the combined process mentioned first will be discussed and first results will be presented.

\section{State of the art}

Currently, there only exists a low number of published studies available concerning the specific combination of backward cup extrusion and piercing, i.e. the performance of backward cup extrusion and piercing in one tool during single press stroke. Within investigations on combined extrusion processes of forward cup extrusion and backward cup extrusion it has been reported on certain geometric conditions of the piercing of the previously pressed pin in [3] and [4]. In [5] a forming of the shearing zone was observed for the investigated heights of the workpieces:

$$
0,4<\frac{\mathrm{h}}{\emptyset \mathrm{D}}<1
$$

and the choice of ratio of

$$
\varepsilon_{Z}<\frac{\emptyset D_{p i n}^{2}}{\emptyset D_{i}^{2}}<1
$$

This procedure has been defined as a process limit of combined extrusion processes in all three publications and has therefore not been investigated any further. In [6] the topic combined extrusion using backward cup extrusion, forward cup extrusion and piercing, in which the remaining cup bottom is pierced by multiple-acting hydraulic press, is addressed. However, process-specific details of the combined processes of backward cup extrusion and piercing are not dealt with in [6]. In [7] a multi-stage production process of hollow preforms is described, in which a cylindrical workpiece is pierced in one forming stage. This operation leads to a material flow against the direction of the movement of the punch. However, no general information can be found regarding influencing factors and target parameters on the process. Another process description for combined extrusion and piercing can be found in [8].

In [9] hot-backward cup extrusion has been investigated with a controlled counterpunch for ferrous and non-ferrous metals. It is pointed out that the complexity of shape of component can be increased by a subsequent piercing of the cup. The focus of the investigations in [9] is on the reduction of the punch force by using a controlled counterpunch movement.

In $[10,11,12,13,14]$ investigations on combined precision forging and piercing have been performed. Initially, basics of the process are examined using a forged disc having a central hole, which was produced in 
a single forming operation. In $[10,11]$ these fundamental results are transferred to a suspension part.

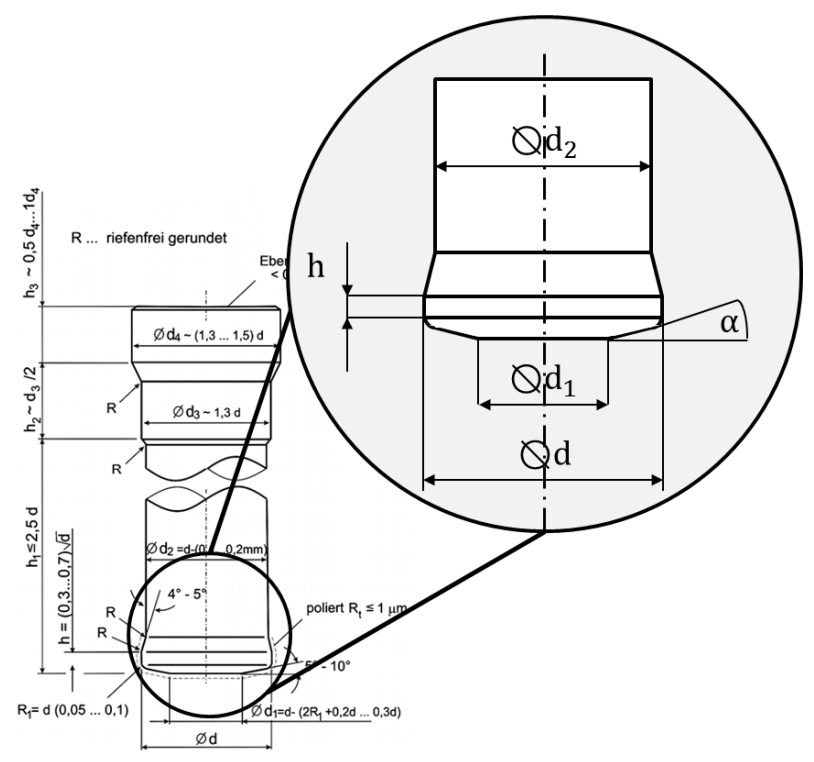

Figure 3. Geometrical properties of punch

Conducted investigation includes the influence of different punch geometries (e.g. figure 3), forming temperatures, tool and workpiece materials as well as the use of weight on the target parameter's hardness, microstructure, wear behavior, compliance with the shape and dimensional tolerances of the hole produced, and the surface quality.

[13] said that the hole produced by process combination is barrel-shaped. These observations are confirmed in $[10,11]$ and it was determined that an influence of the grain structure in interaction with the direction of the punch's movement exists. When arranging grain structure and punch movement direction parallel, barrel-shaped form deviations develop. However, grain structures of the forged parts which point vertically towards the moving direction of the punch lead to conical shape deviations with a larger diameter of hole in the area of the fractured surface. With regard to the shape tolerances of the hole produced it was described in [14] that the smaller the height of level in the area of the shearing zone, the greater the deviation in shape of the hole produced.

In $[12,10,11,14]$ neither influence of the punch's geometry nor an influence of residual mirror height on the surface quality of the hole was discovered.

The investigations of $[12,14,13,11,10]$ with regard to combined precision forging and piercing show that little or only very few analogies exist between the punching of forged parts and the piercing of cold extruded parts. This becomes apparent for example in [10], where it is stated that the surface quality of the fracture surface of the hole is higher than the surface quality of the part produced when forming the holes. In investigations performed by the Institute for Metal Forming Technology differing results have been obtained for penetrating and piercing cold extruded parts.

\section{Numerical investigations of new process arrangement}

This chapter describes the development of simulation models and numerical development of the combination process. Numerical investigation of the combined processes is carried out to identify the significant process parameters. These results are used to define the design of the experimental tooling and the geometrical process parameters.

Within this publication the combination of backward cup extrusion and piercing will be presented as well as the corresponding numerical preliminary investigations such as design of the critical tools, force-displacement curve of the entire process, and a first look at the numerical investigation of the piercing process will be given.

In Figure 4 the concept of the combined process is shown, in particularly the forming process of backward cup extrusion and piercing. The experimental tooling assembly includes punch (1), die (2), counter punch (4), and counter sleeve (3). In this case the critical tooling part is the counter sleeve, which is analyzed in a numerical investigation using DEFORM 2D.

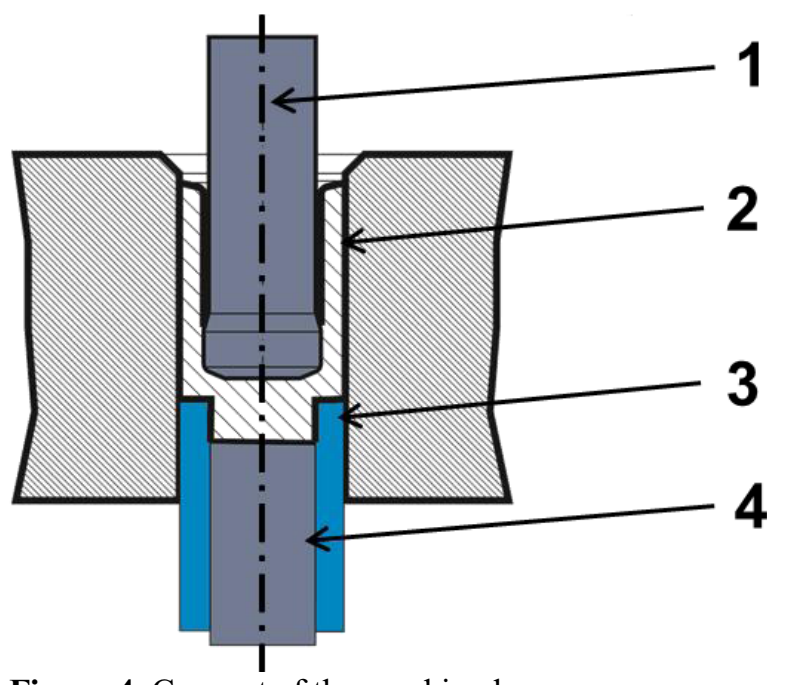

Figure 4. Concept of the combined process

The tools (punch, die and counter sleeve) were simulated as rigid objects in the numerical investigation. The workpiece was simulated as a plastic body having 3240 elements in the 2D simulation and the material $16 \mathrm{MnCr} 5$ was used. The diameter of the workpiece was $16 \mathrm{~mm}$ and initial height was $18 \mathrm{~mm}$.

The velocity of the punch was chosen to $10 \mathrm{~mm} / \mathrm{sec}$ in simulation. The velocity of counterpunch was variated in the simulation to create hydrostatic stress in the shearing zone. The development of crack initiation can be controlled by the hydrostatic stress, 


\subsection{Force displacement curve of combined process sequence}

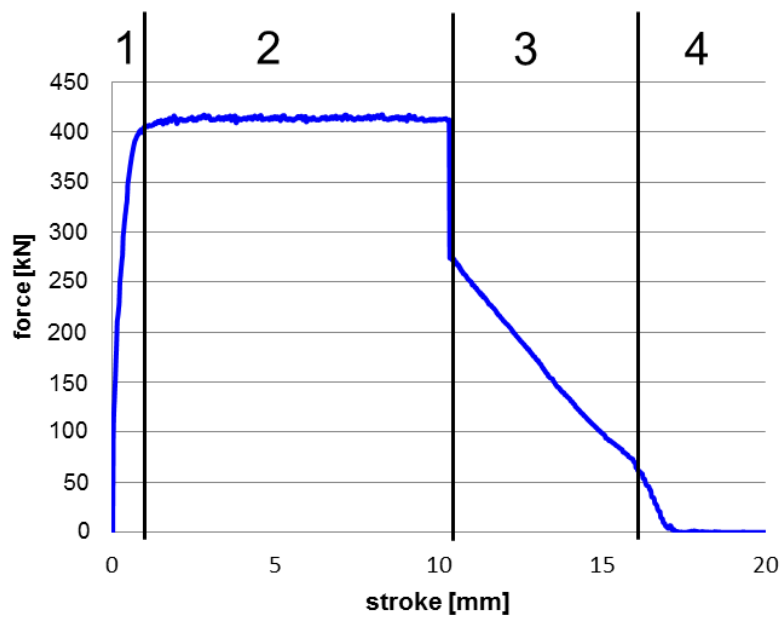

Figure 5. Force displacement curve of combined process sequence

In Figure 5 the force-displacement curve of the punch during the forming process is depicted in the numerical investigation. The force-displacement-curve can be divided into four sections. The first section is the instationary area which is characterized by a rapid increase in force to a maximum value of $\mathrm{F}=417.6 \mathrm{kN}$. In the second section, the specimen is formed at constant punch force. The nearly vertical drop in force to $\Delta \mathrm{F}=138.7 \mathrm{kN}$ during the transition from the second to the third segment identifies the start of the counter punch movement at $\mathrm{h} 1=10.3 \mathrm{~mm}$. Thus, begins the piercing process and the force decreases linearly down to $\mathrm{F}=80.5 \mathrm{kN}$ by the end of the third section. The actual piercing process begins as a result of the crack formation at the start of section four.

\subsection{Stress distribution}

In Fig. 6, the stress distribution during the forming process can be seen. Three different stress conditions are discovered in the workpiece. The first stress state develops during the backward cup extrusion. Furthermore, the highest stresses occur below the punch and are evenly distributed over the entire diameter. With increasing distance to the punch, stresses once more decrease. The high stresses around the punch mean that the material flow in this area is the largest and most of the material is pressed into the gap between the punch and the die by the punch itself.

As the counterpunch starts to move, the next part of the process begins. During this section different stress distributions are the result (see Fig.6). The highest stresses occur between the punch edge and the outer edge of the inside of the counter sleeve and reduce towards the center of the punch and towards the wall of the die. The stresses in the shearing zone increase the further the punch moves until the defined, critical value of the damage model is reached. In this numerical investigation the Cockcroft \& Latham equation is used:

$$
\int^{\bar{s}} \frac{\bar{\sigma}}{\bar{\sigma}^{*}} d \bar{\varepsilon}=0,7
$$

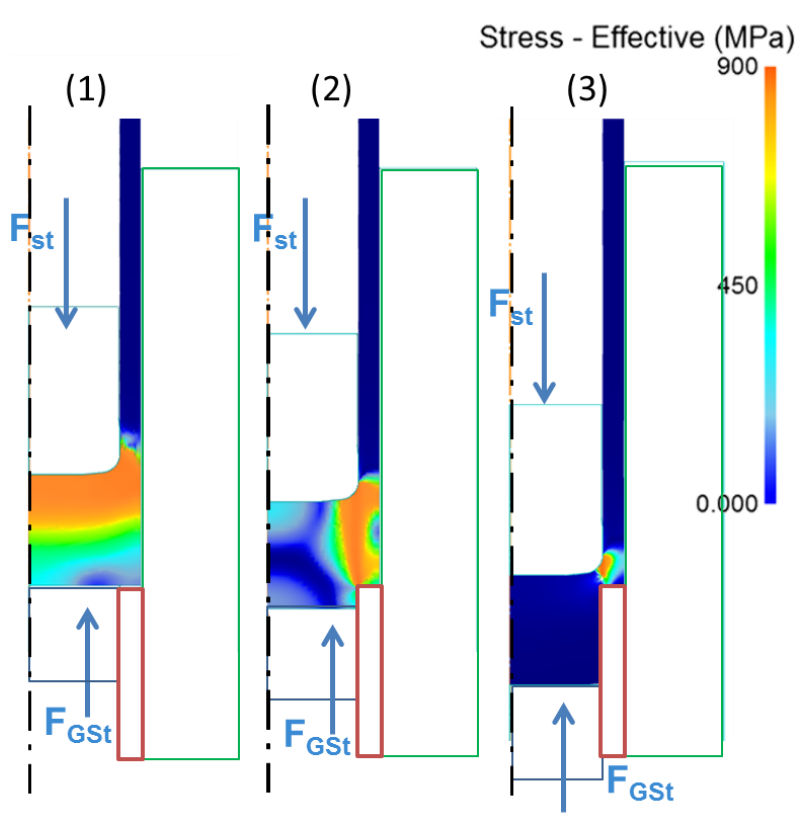

Figure 6. Stress distribution during piercing

After the initiation of the cracks, the stress distribution changes (Fig. 7 see.). While the cracks are spreading, the stresses relocate in areas, in which the workpiece is undamaged still. However, in these areas no further stresses can be generated.

As the forming process goes on, the stress changes from a hydrostatic stress state into a state of tension. The tensile stresses increase until reaching the point of separation resistance, which is why cracks occur and therefore, stresses and strains in the workpiece reduce. This sequence repeats itself throughout the piercing process and is responsible for the extension of the cracks.
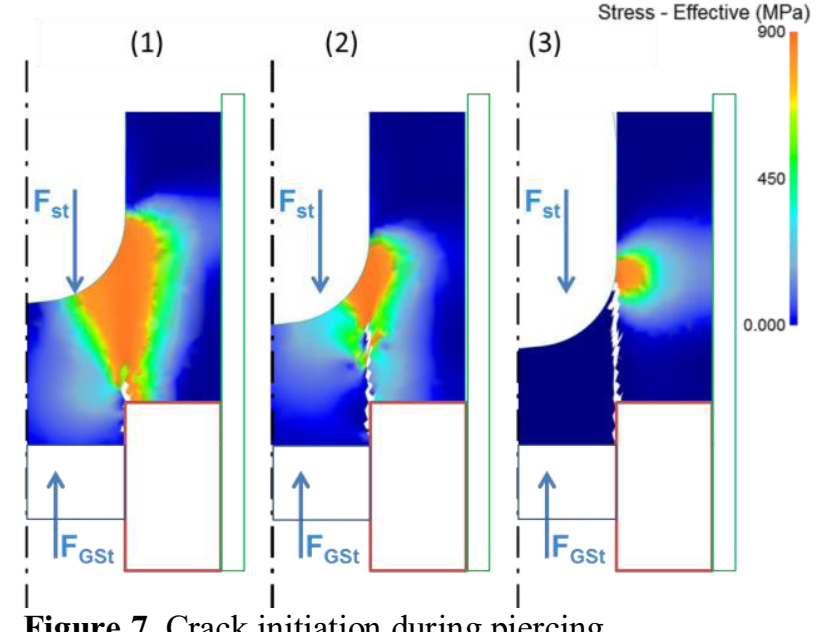

Figure 7. Crack initiation during piercing 


\subsection{Load simulation of the counter sleeve}

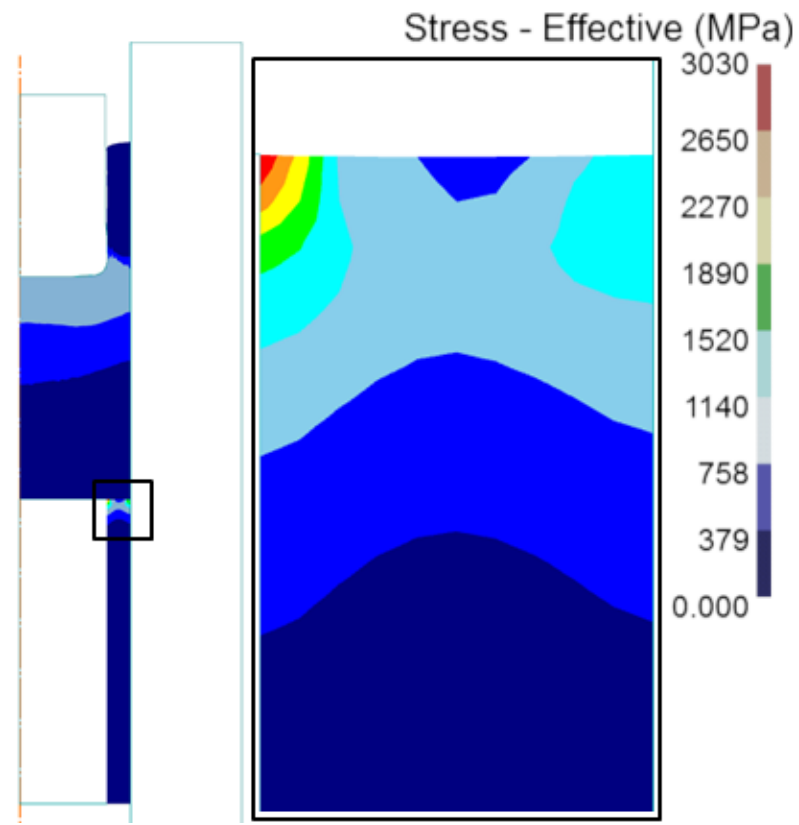

Figure 8. Load simulation of the counter sleeve for $\mathrm{s}=1,6 \mathrm{~mm}$

In Figure 8 the load of the counter sleeve is depicted. Therefore, different numerical investigations were performed prior to the process. The aim was reducing the wall thickness of the counter sleeve and reaching the minimum of the wall thickness. The numerical investigation has shown that a sufficient wall thickness of the counter sleeve is necessary.

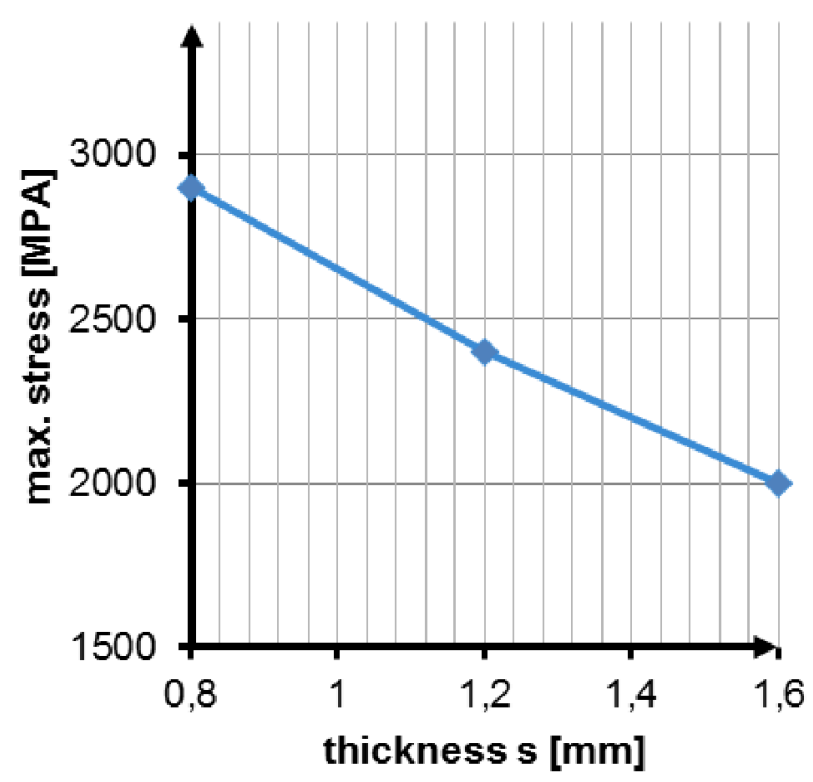

Figure 9. Load for different thickness of the counter sleeve

The maximum stress of the counter sleeve must be between $2000 \mathrm{MPa}$ and $2500 \mathrm{MPa}$, in which case standard tool steel can be used. This means the wall thickness of the counter sleeve must be higher than $1,3 \mathrm{~mm}$ (e.g. figure 9).

\section{Outlook and further investigation}

In future investigations numerical optimization of backward cup extrusion will be examined and numerical studies with regard to the influence of the controlled counterpunch will be carried out for the stress states in the shearing zone.

After the numerical investigation, the design and production of the experimental tooling (e.g. figure 10) will be performed. The process factors will be parametrized and integrated into the control of the tooling and the press control.

Furthermore, experimental investigation will be performed to identify significant process parameters and determine the process limits of combining processes and validate numerical investigations.

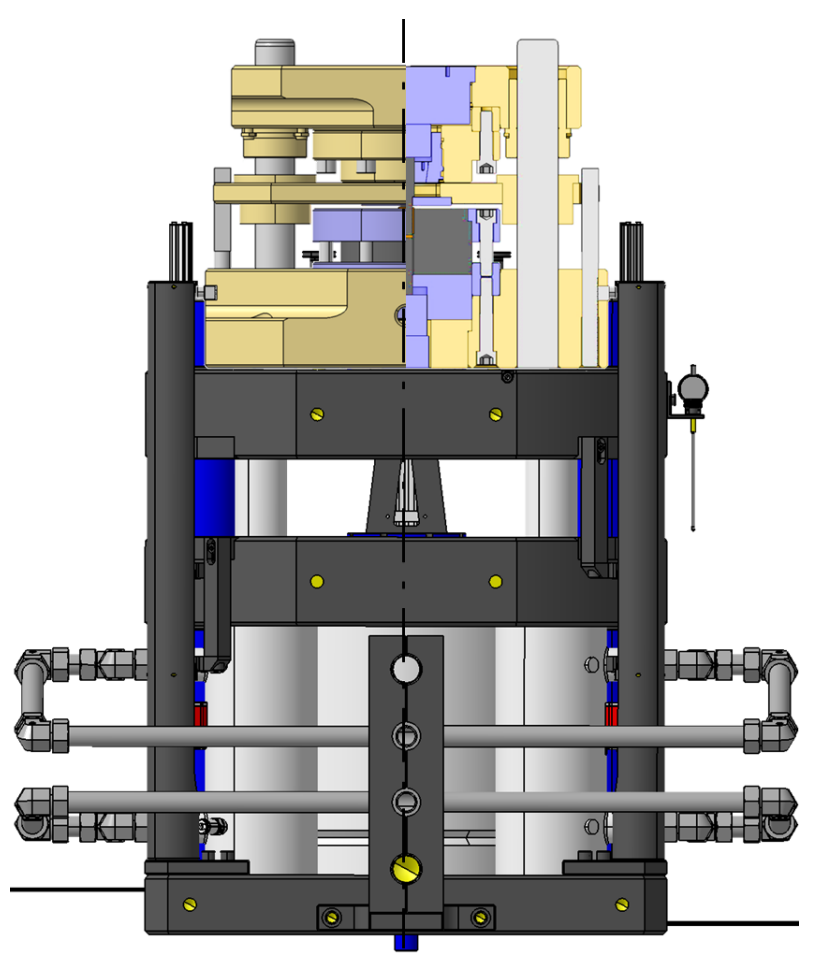

Figure 10. Newly developed tooling for combined extrusion and piercing

Evaluation of numerical and experimental results as well as the determination of technological and functional improvements of the hollow preforms with regard to the conventional process sequence will be carried out within the framework of this research project also.

Based on the results of the project, guidelines referring to dimensionless influencing and targeting parameters are to be developed, which makes designing those combined processes easier and makes transferring these results to industrial part geometries possible.

\section{Acknowledgement}

The IGF project $18431 \mathrm{~N}$ of the "Forschungsvereinigung Stahlverformung e.V. (FSV)" was funded by the AIF 
within the framework of promoting industrial research and development (IGF) by the German Federal Ministry of Economics and Technology.

The authors would like to thank "Arbeitsgemeinschaft industrieller Forschungsvereinigungen (AiF)" for their financial support with regard to the research project „Erzeugung rohrförmiger Halbzeuge durch die Kombination der Umform-verfahren NapfRückwärtsfließpressen und Lochen“".

\section{References}

1. M. Liewald, A. Felde, T. Schiemann, GCFG report (2009)

2. C. Mletzko et al., SchmiedeJOURNAL, H. 2 o. Jg. (2012)

3. J.-F. Adie, J.-M. Alexander, Proc. Instn. Mech. Engrs. 182, 249-259 (1967-68)

4. W.-D. Graf, H. Schnorrbusch, Zeitschr. f. Techn. u. Organ. / Kammer d. Tech., Fachverband Maschinenbau, 23, 535-539 (1973)

5. K. DaChang et al, J. of Materials Proc. Techn., 117, 15-20 (2001)

6. H. Yoshimura, K. Tanaka, J. of Materials Proc. Techn., 98, 196-204 (2000)

7. J. Klimczak, patent DE 102009016654 A1, (2010)

8. R. Mauermann, patent DD 231506 A1, (1986)

9. C.-W Jaschajaev, Kuznezno-stampowoznoje proizwodstwo, 9, 4-6 (1966)

10. B.-A Behrens, J. Kerkling, Prod. Eng. Res. Devel., 5, 201-207 (2011)

11. B.-A Behrens, R Nickel, J. Kerkling, Int. J Mater Form, 5, 301-306 (2012)

12. K. Kerkling, K. Müller, B.-A. Behrens, Werkstattstechnik online, 100, H. 6, 535-540 (2010)

13. B.-A Behrens, S. Reinsch, A Schott, E. Meyer, Prod. Eng., 13, H.2, 87-90 (2006)

14. E. Meyer, A. Schott, Schmiedejournal, o. Jg., 16-18, (2005) 